\title{
QUELQUES RÉFLEXIONS SUR LA DIFFICULTÉ À CONCEVOIR L'ÉTRANGER EN EUROPE CENTRALE. LE CAS SLOVAQUE DANS LES PREMIÈRES DÉCENNIES DU XX $X^{E}$ SIÈCLE
}

\author{
Etienne Boisserie
}

\begin{abstract}
This paper contains some reflexions on the difficulty to conceive the stranger in the Central Europe, presenting, in particular, the case of Slovakia in the first decades of the $20^{\text {th }}$ century.

Keywords: Slovakia; Hungarian kingdom; First World War; Slovaks-Hungarians (mutual relations).

Résumé : Cet article contient quelques réflexions sur la difficulté à concevoir l'étranger en Europe centrale, présentant surtout le cas slovaque dans les premières décennies du XXe siècle.

Mots clés : Slovaquie ; royaume de Hongrie ; Première Guerre mondiale ; Slovaques-Hongrois (relations mutuelles).
\end{abstract}

L'idée qui sous-tend cet article est la suivante : le territoire slovaque, comme d'autres notamment centre-européens a longtemps, et souvent, fait l'objet d'une description binaire : soit comme un territoire appartenant à une nation ou à un cadre dit "national » - quelle qu'il soit, hongroise ou slovaque essentiellement -, soit comme un lieu de conflit latent entre majorité et minorité, catégories progressivement étanchéifiées. ${ }^{1} \mathrm{Ni}$ l'une ni l'autre des approches ne correspondent à la complexité du développement humain et politique de ce territoire ni ne permettent de les comprendre. Si elles sont désormais remises en cause, $c^{\prime}$ est en particulier en raison de leur absence de prise en compte de différents niveaux d'interactions qu'une histoire essentiellement politique a jusqu'alors mal mesurés.

Il est en effet utile de s'interroger sur les croisements de loyautés multiples, et parfois contradictoires, sur les variations du primat de l'élément culturel, linguistique ou religieux d'une part et sur la nature du lien historique d'autre part. Il n'est pas moins utile d'observer la perception d'espaces d'apparence périphériques, qui peuvent être perçus sous le double signe d'une identité et d'une altérité (Magyars de Slovaquie et Hongrie ;

\footnotetext{
1 Certains passages de ce texte sont empruntés, dans une version remaniée et précisée à l'introduction de E. Boisserie, C. Royer (dir.) in Miroirs brisés, Récits régionaux et imaginaires croisés sur le territoire slovaque, Paris, Institut d'études slaves - CIRCE, 2011.
} 
Slovaques et Tchèques, Allemands de l'intérieur et de l'extérieur). L'observation des compositions et recompositions politiques qui peuvent s'opérer au nom de la prévalence - même provisoire - d'un élément d'altérité significatif n'est pas moins significative. La dimension infra-régionale, locale, ne peut pas être occultée, pas plus que ne peuvent l'être les micro-altérités qu' elle produit. Il semble enfin indispensable de tenir à égale distance l'approche la plus classique d'une opposition frontale sur une base exclusivement ethno-linguistique ou culturelle d'une part, et la vision irénique d'une multiculturalité naturelle et fructueuse d'autre part.

Évoquer la question de l'étranger ne se limite donc pas à une relation (opposition) majorité/minorité. Si être étranger, c'est primordialement "ne pas appartenir à », cette non appartenance peut se regarder à différentes échelles : l'État, la nation, la communauté, la région, la ville, le groupe, la famille ; elle est plastique, faite de déplacement et de superpositions. Plusieurs dimensions peuvent se croiser, à la fois dans le temps et dans l'espace. Difficile à saisir dans un environnement politique, social, géographique stable, a fortiori dans des temps de recompositions sociales et politiques majeures, de transformations démographiques et humaines, dans un espace géographique lui-même incertain, la notion d'étranger peut être observée sous différents angles. Nous privilégions ici une séquence chronologique courte - la deuxième décennie du XXe siècle - dans un espace réduit - le territoire de l'actuelle République slovaque - et complexe, espérant ainsi offrir quelques pistes de réflexion privilégiant la fluidité des relations plutôt que leur opposition frontale.

Cela suppose de s'intéresser en premier lieu à l'espace dont il est question et dont la définition n'a rien d'une évidence. Pour des raisons qui tiennent au temps et à la compétence, je centrerai ici mon propos sur les Slovaques, et sur la relation entretenue avec $\mathrm{d}^{\prime}$ autres composantes dites « nationales » du territoire dans une triple dimension, chronologique, spatiale et nationale.

\section{Éléments d'un contexte chronologique}

Au risque de rappeler des éléments connus, le premier $x x^{e}$ siècle en Slovaquie est scandé par plusieurs ruptures entre périodes : ces ruptures ont un impact institutionnel, humain et géographique : avant 1918, appartenance de l'ensemble du territoire aujourd'hui slovaque au royaume de Hongrie, lui-même inclut dans la monarchie austro-hongroise. Jusqu'à cette date, la Slovaquie, telle qu'elle est définie aujourd'hui n'existe pas - ce qui ne signifie pas absence de réflexion sur son périmètre. De 1918 à 1938, le territoire est construit, défini progressivement par la fixation de frontières étatiques puis administratives, lui donnant une définition et une population qu'il perd en partie en 1938 - par l'arbitrage de Vienne du 2 novembre 1938, conséquence des accords de Munich. De 1938 à 1945, l'espace slovaque réduit territorialement et transformé humainement, plus conforme spatialement à ses représentations les plus courantes du XIX ${ }^{\mathrm{e}}$ siècle est représenté sur un mode irrédent comme amputé. En 1945 enfin, il retrouve - à quelques kilomètres carrés près, sa forme de 1937.

Ces transformations géographiques accompagnèrent ou furent concomitantes à des changements institutionnels majeurs. Avant 1918, ce territoire s'inscrit dans l'histoire du royaume de Hongrie, avec une doctrine d'État - celle de la nation politique hongroise - qui postule une unité civique et politique reposant sur une forme d’homogénéisation 
Quelques réflexions sur la difficulté à concevoir l'étranger en Europe centrale...

culturelle $^{2}$; De 1918 à 1938, la doctrine de la nation unitaire tchécoslovaque promeut une identité entre Tchèques et Slovaques, qui appartiendraient tout ensemble à une seule nation «tchécoslovaque »; À partir de 1938 - et surtout de mars 1939 - l'affirmation institutionnelle et la création d'un État slovaque propre imposent un récit fondé sur l'aboutissement du combat de la nation (slovaque) pour elle-même et revendique une analyse principalement négative des périodes précédentes, conçues comme oppressives et relevant à des degrés divers de la domination étrangère. ${ }^{3}$ Sur le plan historiographique, la construction d'un récit unitariste, tchécoslovaque, qui s'était substitué au récit hongrois, est supplanté à son tour par une contre histoire centrée sur le développement propre des Slovaques qui était la caractéristique des récits politico-historiques slovaques de l'immédiat avant-guerre. ${ }^{4}$ Ces caractéristiques n'épuisent pas le sujet, mais elles sont dominantes. De 1938 à 1945, la lutte pour un combat de libération « nationale », entendre slovaque, submerge le récit national. L'exclusion de la dimension hongroise de cette histoire - récit d'opposition frontale qui appuie celui, plus politique, proposé sur les territoires perdus par l'arbitrage de Vienne. L'ensemble de ces grandes narrations, qu'elles soient complémentaires ou concurrentes, construit des blocs figés, le plus souvent construit sur une base nationale ou, parfois, confessionnelle.

Au fil de ces trois grandes périodes donc, la Slovaquie connaît trois États, trois définitions territoriales, trois régimes politiques, trois grands récits historiques. Cette situation a des effets sur les perceptions successives de soi et de l'étranger dans deux dimensions ; territoriale et nationale. La définition du territoire est incertaine, celle de la nation l'est tout autant.

\section{Interroger les contours de la nation dans son espace}

L'interrogation persistante sur les contours de la «nation » est une des raisons pour lesquelles l'étranger l'est rarement de manière radicale ou complète. Les différentes formes de rattachement à la nation ou au territoire interdisent de penser - sauf exceptions sur lesquelles nous reviendrons - l'étranger de manière radicale.

Le territoire, comme espace où se déroule prioritairement le récit national - le pluriel pouvant être utilisé sans peine -, n'est pas simple d'abord. Il est construit progressivement et n'est pas exactement identique au territoire défini en 1918-1920. Cette difficulté à saisir ce territoire comme un tout apparaît par l'étude, même succincte, de ce que recouvrit le terme "Slovaquie» dans la réflexion slovaque au XIX ${ }^{\mathrm{e}}$ siècle. En effet, dès lors que ce terme devint courant, les Slovaques s'interrogèrent sur le périmètre de la «Slovaquie ». Les espaces périphériques y étaient nombreux, tant les frontières administratives et ethniques manquaient de congruence, les zones de feuilletage y étaient plus fréquentes que les régions constituées symboliquement en cœur de la « vie nationale ».

Le territoire slovaque offre en effet une singularité : ses limites géographiques n'intéressèrent longtemps qu'une poignée de patriotes slovaques, et ceci dans une acception essentiellement linguistique et culturelle. Les premières tentatives de délimitations d'un

\footnotetext{
2 Voir László Szarka, Szlovák nemzeti fejlődés - Magyar nemzetiségi politika 1867-1918 / Slovenský národný vývin Národnostná politika v Uhorsku 1867-1918, Bratislava, Kalligram, 1999 ; Ladislav Vörös, Slováci v národnostnej politike Štefana Tiszu v rokoch 1913-1917, Diplomová práca, Filozofická fakulta univerzity Komenského - Katedra slovenských dejín a archivníctva, Bratislava, 2001.

3 Voir notamment František Hrušovský, Slovenské dejiny, T. S. Martin, Matica slovenská, 1939.

4 Voir notamment František Vit'azoslav Sasinek, Slováci v Uhorsku, T. S. Martin, KÚS, 1905 (2e édition, revue et corrigée).
} 
espace slovaque datent du XVIII ${ }^{\mathrm{e}}$ siècle et restèrent longtemps marquées par la dimension ethnographique. ${ }^{5}$ Ján Čaplovič offrit la première tentative concrète de délimitation dans Etnografia Slovákov v Uhorsku ${ }^{6}$ et la précisa dans la carte annexée à son Gemälde von Ungarn (1829). Par ailleurs riches en élaborations territoriales, les années 1830-1840 s'appuyaient en priorité sur la dimension linguistique. ${ }^{7}$

La question du territoire s'inscrivait dans une réflexion sur le concept de "patrie» pour lequel la langue slovaque connaît deux termes : le premier, vlast', a une dimension historique et institutionnelle ; Il souligne le lien à l'État et à son histoire. Le second, otčina, recouvre en revanche la dimension ethno-culturelle de la commune appartenance, et considère la patrie comme une entité collective à l'intérieur du royaume de Hongrie. Peu à peu, on identifia cette otčina au territoire habité par les Slovaques. Dans les années 1840 , l'usage du terme «Slovaquie » commença à se répandre : il recouvrait un espace ne représentant qu'une large partie du nord de la Slovaquie d'aujourd'hui.

Dans Une voix de Slovaquie publié en janvier 1861 puis dans le « Mémorandum de la nation slovaque » de la même année, l'homme politique et publiciste slovaque Štefan Marko Daxner (1822-1892) tenta à son tour de délimiter l'espace slovaque. ${ }^{8}$ Il y définit un territoire des Slaves de Hongrie septentrionale (severo-uhorski Slaviani), s'étendant depuis Bratislava et la frontière morave jusqu'en Galicie et en Bucovine. Deux langues, le slovaque à l'Ouest, le ruthène à l'Est, se le partagent et se mélangent dans les plaines de la Topl'a, et entre Ondava et Laborec dans le comitat de Zemplín. Daxner offrait donc une vision extensive à l'Est, dénuée de toute frontière méridionale fixée avec certitude, et tentait de définir un espace où les Slovaques, peuple autochtone, étaient titulaires de droits culturels et linguistiques. ${ }^{9}$ Il s'appuyait pour justifier son projet sur la nécessité d'une consolidation interne de la Hongrie et de la préservation de son intégrité. ${ }^{10}$

Ce document fondateur de la politique slovaque pour les soixante années à venir posa le principe d'un territoire national sans pouvoir le définir. Ce n'est un paradoxe qu'en apparence. Au début du XXe siècle, le dictionnaire encyclopédique Otto n'était pas plus en mesure de définir un territoire "slovaque » autrement qu'en s'appuyant largement sur une base ethnique, et en débordant sur l'Est de la Moravie et le Nord-est de l'Autriche. ${ }^{11}$ À la veille de la Première Guerre mondiale, il n'existait donc pas de conception claire du territoire slovaque. Pour les Slovaques, seuls à la considérer, la question de sa délimitation restait essentiellement posée en termes ethnolinguistiques. Sur un plan pratique, ces questions furent de peu d'importance dans la mesure où, progressivement, la partie «territorialisée » des demandes de 1861 disparut du programme «national » slovaque. ${ }^{12}$ Après 1918, la définition - même incomplète - d'une «Slovaquie » aurait dû

5 Libuša Franková, «K formovaniu predstáv o slovenskom etnickom území v národných obranách v prvej polovici 19. storočia », Dejiny (Internetový časopis Inštitútu histórie FF PU v Prešove), n 1, 2006, p. 7-15.

6 Republié dans une édition traduite annotée et postfacée par Ruda Brtáň, Etnografia Slovákov v Uhorsku, Bratislava, Slovenské pedagogické nakladatel'stvo, 1997.

7 Pour les détails, voir Libuša Franková, art. cit.

8 Štefan Marko Daxner, Hlas zo Slovenska, Pest, Trattner-Károly, 1861.

9 Ibid., p. 6.

10 Sur la conception de la relation hungaro-slovaque chez Daxner, voir Étienne Boisserie, «Les Voies étroites d'une historiographie nationale. La construction d'un canon historique slovaque au XIXe siècle ", in Michel Maslowski, Paul Gradvohl, Didier Francfort (dir.), Canons de la culture et visions de l'histoire en Europe centrale, Paris, Institut d'études slaves, 2010, p. 305-326.

11 Ottův slovnik naučny (23 e tome), Prague, 1905, p. 406.

12 Voir Milan Podrimavský, Slovenská národná strana v druhej polovici 19. storočia, Bratislava, Veda, 1983 et, plus récemment, László Szarka, op. cit. 
en modifier l'approche et penser les diversités de ce territoire enfin borné. Ce ne fut pas le cas.

En effet, au début du XXe siècle, s'appuyant sur les réflexions qui viennent d'être brièvement rappelées, l'un des fondateurs de l'historiographie slovaque, František V. Sasinek réaffirma le principe de l'existence d'une nation séparée, vivant sur son propre territoire. Son histoire des Slovaques avait un objectif : démontrer le caractère autochtone des Slovaques sur une partie du territoire de la Haute Hongrie et lui donner une histoire écrite. ${ }^{13}$ Le territoire proposé par Sasinek correspond à la représentation d'un territoire slovaque à l'époque, concentré dans cinq comitats, - 14 si l'on tient compte de l'approche du « Mémorandum » de 1861 qui servait le plus souvent de référence - sur les 19 comitats hongrois qui couvraient le territoire devenu la Slovaquie.

Jusqu'en 1918 en effet, le cadre d'une histoire slovaque est défini par la présence de populations dite «slovaques » suffisamment denses. Cette phase de tentative de définition du corps national laisse ouverte certaines questions, notamment dans la partie orientale comme en témoigne le débat qui oppose des ethnologues - et notamment Samuel Czambel ${ }^{14}$ ou le Tchèque Lubor Niederle ${ }^{15}$ - aux intellectuels de Martin sur la limite entre monde slovaque et ruthène. Au-delà de sa dimension "nationale ", cette interrogation a une dimension confessionnelle que traduit l'un des axes du débat: «De quelle confession sont les Slovaques ? » [« Akej viery sú Slováci »] s'interroge ainsi Jozef Škultéty dans un important article publié par les Slovenské Pohl'ady en 1895. Enfin, l'histoire des Slovaques écrite à cette époque n'englobe pas - ou très peu - le territoire au Sud d'une ligne Bratislava - Zvolen - Lučenec - Košice, considéré comme ayant une part limitée dans ce récit national. Au début du $X X^{e}$ siècle, l'angle privilégié est donc une histoire des Slovaques sur un territoire peu étendu. Double réduction territoriale et humaine, inscrite dans une tradition historiographique aujourd'hui qualifiée de " dissidente » et qui a laissé des traces. La ligne de démarcation négociée par Hodža à Budapest en novembre 1918 reprend cette délimitation géographique entre la «Slovaquie » et la Hongrie.

\section{Remettre en perspective l'approche territoriale de l'histoire slovaque}

L'histoire de ce territoire ne peut donc pas être abordée sur un mode homogène avant 1918. Outre la réflexion sur les frontières, il faut aussi se pencher sur les effets des enclavements ou les différences régionales. Loin de constituer un espace clos et délimité par des frontières étatiques ou historiques, ce territoire est à la fois très ouvert et fortement enclavé. Pensé comme un tout homogène dès lors que ses frontières furent fixées, il n'en était pas moins durablement fractionné et constitué de régions aux évolutions historiques, humaines et économiques variées, vivant des relations spécifiques à chacune de leurs marges. Dans un ouvrage initialement publié en 1920 et devenu classique malgré ses limites, Ján Lajčiak soulignait ces différences régionales, y compris dans des régions ultérieurement décrites comme homogènes : «Il est vrai que le noyau des habitants de Slovaquie vit dans les régions montagneuses de Haute Hongrie [dont] la topographie

\footnotetext{
${ }^{13}$ František Vit'azoslav Sasinek, Slováci v Uhorsku, Turčiansky Sväty Martin, KÚS, 1905 (2édition, revue et corrigée) et, du même auteur, Dejepis Slovákov, Ružomberok, Karol Salva.

14 Samuel Czambel, Slovenská reč a jej miesto v rodine slovanských jazykov. I. Východoslovenské nářečie, Martin, Kníhtlačiarsky účastinársky spolok (KÚS), 1906.

15 Lubor Niederle, Národopisná mapa uherských Slováků na základě sčitání lidu z roku 1900, Praha, 1903.
} 
offre une grande variété qui n'est pas sans effet sur le caractère des différentes régions slovaques... La circonstance que les villages slovaques mènent une vie isolée a créé des types particuliers. On peut s'en convaincre lorsqu'on se rend d'un village ou d'une région à $l^{\prime}$ autre ${ }^{16}$. »

Tout au long du XIXe siècle, l'idée d'une pluralité de «Slovaquie » a pris les traits d'un topos. Même sur un territoire plus réduit que l'actuel, les différences régionales et infra régionales sont marquées, la mobilité des populations rendue complexe par la géographie, par la faiblesse des infrastructures ou la nature des structures sociales. Même sommairement envisagée, une tripartition territoriale fait apparaître de nombreux espaces ouverts. Les régions occidentales, influencées par leur proximité avec la Moravie, l'Autriche et l'Ouest du royaume de Hongrie, entretenaient des contacts plus étroits avec de grands centres urbains et absorbaient plus aisément leurs influences culturelles. La Slovaquie centrale, même dominée jusque tardivement par une culture pastorale associée à des éléments de l'identité slovaque, est marquée par l'héritage minier, l'importance d'anciennes villes royales à forte composante allemande et la proximité de Budapest. La dimension rurale, souvent associée à la slovacité, ne résume pas les spécificités de ces régions. L'Est enfin présentait une diversité frappante ${ }^{17}$, entre sous-développement et micro-régions très riches sur le plan culturel, bénéficiant souvent des effets d'une modernisation apportée par les réémigrants de retour d'Amérique du Nord - sans omettre les particularités du Gemer ou du Spiš, à forte composante allemande et/ou protestante, régions parfois plus industrialisées et bénéficiant d'un niveau d'instruction moyen supérieur.

Il est également utile d'analyser les liens de chacune des parties du territoire du territoire de la Haute Hongrie avec la plaine hongroise en général et avec Budapest en particulier au début du $X X^{e}$ siècle. L'outillage mental exclut l'idée d'appartenance à un territoire slovaque pour une grande partie de ces habitants et fait prévaloir d'autres attracteurs, qui lui sont extérieurs. Poser la question de la relation ou des interactions entre l'actuel territoire slovaque et son environnement méridional, c'est aussi réfléchir sur les effets d'enclavements créés par le tracé des frontières de 1920 (en particulier dans les régions, telles le Gemer, développées par le commerce de minerai et de matières premières avec Budapest).

Ces différences régionales reposent aussi sur des éléments linguistiques et culturels. Même dans une conception étroite, le territoire slovaque n'abrite pas que des Slovaques. Citons de nouveau Ján Lajčiak : «La Slovaquie (entendre «les Slovaques », NDA) vit en relation directe avec les Hongrois, les Tchèques, les Polonais, les Allemands, les Ruthènes et les Serbes. Que ces nations aient eu une influence considérable sur la constitution de la nation slovaque est clair pour tout observateur un tant soit peu objectif ${ }^{18}$. » Ces populations allogènes étaient elles-mêmes hétérogènes et morcelées géographiquement ou socialement. Par ailleurs, toutes ne furent pas sensibles dans les mêmes proportions au processus de magyarisation qui revêtit des formes très variées, selon que l'on considère les chiffres bruts des recensements hongrois ou que l'on fait intervenir d'autres indicateurs comme la polyglossie.

\footnotetext{
16 Ján Lajčiak, Slovensko a kultúra, rééd. Bratislava, Q111, 2007, p. 55 (1 édition: Bratislava, Slov. Ev. a v. Theol. Akademia, 1920).

17 Peter Švorc (dir.), Spiš v koninuite času, Prešov - Wien, Universum, 1995.

${ }_{18}$ Ján Lajčiak, op. cit., p. 53.
} 
Quelques réflexions sur la difficulté à concevoir l'étranger en Europe centrale...

Ainsi, quelle qu'ait été la catégorie «nationale » de la population, la pluralité et l'hétérogénéité des situations demeura une constante. S'il existait des "Allemands de Slovaquie », le pluriel se justifiait, outre des considérations de nombre, par leur histoire, leur statut et leur environnement. Il n'y avait pas une seule population juive en Slovaquie, pas plus qu'une population allemande homogène, mais des Allemands de Bratislava, des villes minières, ou encore du Spiš, d'autres distinctions géographiques plus fines pouvant même être appliquées à ces populations. ${ }^{19}$ De même est-il vain de chercher une unité chez les Slovaques. Au-delà du clivage confessionnel - catholique-protestant - ou des statuts sociaux, la population slovacophone, à supposer qu'elle soit définissable, n'offrait pas d'homogénéité du point de vue national. Par ailleurs, la surévaluation du critère linguistique a occulté trop longtemps le fait que, pour une partie d'entre eux, la loyauté linguistique ne conditionnait pas la loyauté politique ou que le concept de «patrie » pouvait être polysémique. ${ }^{20}$ Les difficultés posées par les loyautés croisées et l'attachement au cadre historique sont en elles-mêmes un objet dont historiens slovaques ${ }^{21}$ ou étrangers ${ }^{22}$ se sont désormais vigoureusement saisis pour remettre en cause une division construite - sur un mode parfois accusatoire - à l'aide de catégories étanches. Les écrits politiques d'Ivan Dérer, personnalité de premier plan de la social-démocratie slovaque de l'entre-deux-guerres, constituaient une illustration de ce découpage aujourd'hui dépassé $^{23}$. Lorsqu'il catégorisait la population slovaque des décennies précédant la guerre, Dérer distinguait trois groupes : un premier composé de la masse du peuple, très largement privé d'une conscience nationale et disposant d'une conscience étatique (hongroise au sens de "Uhor»), mais non pas nationale au sens de "slovaque » et chez lequel, localement, une conscience de type nationale était "l'exception». Un second groupe, rapidement écarté de la catégorie nationale était constitué de la majorité de l'intelligentsia "dénationalisée », expression renvoyant aux hommes dits "de la vielle génération de Martin » - qu'il ne nomme pas - figures d'un conservatisme national infécond. Le troisième groupe, enfin, se composait d'une toute petite frange de l'intelligentsia suivie par un faible nombre de personnes nationalement conscientes. Cette répartition permettait à Dérer de tirer une conclusion implacable : «l'histoire slovaque est le combat de ce petit groupe de patriotes slovaques ${ }^{24} »$. Dérer cédait ainsi au biais déjà sensible dans le dernier quart du XIX ${ }^{\mathrm{e}}$ siècle qui consiste à décerner le label patriotique et l'exclusivité de l'action historique à une poignée d'hommes, en l'occurrence aux principales figures du rapprochement tchéco-slovaque. Ainsi s'exprimait en outre une vision archétypale d'appropriation d'un histoire territoriale nationalisée puis réduite à un combat de nature

\footnotetext{
19 Jozef Tancer et Elena Mannová, « Od uhorského patriotizmu k menšinovému nacionalizmu. Zmeny povedomia Nemcov na Slovensku v 18. až 20. storočí », in G. Kiliánová, E. Kowalská, E. Krekovičová (dir.), My a tí druhí v modernej spoločnosti, Bratislava, Veda, 2009, p. 351-416.

20 Voir récemment à ce sujet Alexander Maxwell, Choosing Slovakia. Slavic Hungary, the Czechoslovak Language and Accidental Nationalism, Londres et New York, I.B. Tauris Publishers, 2009.

${ }^{21}$ Voir en particulier Elena Mannová, « Koncept lojality. Postoj k autoritám na Slovensku počas prvej svetovej vojny ", Historický časopis, 55e année, 2007, n 4, p. 681-698. Voir aussi László Vörös, Analytická historiografia versus nárdné dejiny. "Národ" ako sociálna reprezentácia, Pisa, Pisa University Press, 2010 ; Ivan Halász, Uhorsko a podoby slovenskej identity $v$ dlhom 19. storočí, Bratislava, Kalligram, 2011.

${ }^{22}$ Ismo Nurmi, Slovakia - A Playground for Nationalism and National Identity 1918-1920, Helsinki, Suomen Historiallinen Seura, 1999 [Société historique finlandaise] ; Elisabeth Bakke, Doomed to Failure? The Czechoslovak nation project and the Slovak autonomist reaction 1918-38, Oslo, Series of Dissertation submitted to the Department of Political Science, Faculty of Social Sciences, University of Oslo, n 11/1999.

${ }^{23}$ Ivan Dérer, Československá otázka, Prague, 1935, et notamment l'étude « Úvahy o československej otázke ».

${ }^{24}$ In ibid., p. 15.
} 
politique, culturel et économique, une vision « dissidente », pour reprendre l'excellente formule de Milan Zemko ${ }^{25}$, qui s' efforce de gommer complexités, feuilletages et altérités.

Ils sont pourtant d'importance comme l'historiographie slovaque actuelle en atteste, qui aborde de nouveaux champs, croise ses approches et ses problématiques avec d'autres disciplines et s'interroge sur la complexité des processus de constructions nationales et/ou régionales ${ }^{26}$, les lieux de mémoire dans leurs différentes $\operatorname{composantes}^{27}$ et plus largement sur la stratification d'un discours historique. ${ }^{28}$ On y mesure le jeu des croisements, des interactions et des influences mutuelles entre différents groupes nationaux et sociaux autant que le rejet - qui peut être partiel ou total - de ces influences. « La Slovaquie ne forme pas une unité territoriale géographiquement fermée..$^{29}$ »C'est ce que peut illustrer l'analyse de la situation au cours de la Première Guerre mondiale.

\section{Les Hongrois et les Slovaques dans la Première Guerre mondiale}

Au moment de la mobilisation l'heure est à l'éloge de l'attitude des conscrits slovaques. Le «peuple slovaque », lit-on en substance, fait la preuve de son amour de la patrie. Les dirigeants du Parti national slovaque, de leur côté, restent considérés avec méfiance. Les soldats slovaques sont perçus comme des combattants valeureux, insensibles au « panslavisme » des dirigeants du Parti national slovaque. Les odes à la commune appartenance sont nombreux et ont un effet sur la double catégorisation fréquemment utilisée jusqu'alors : " uhorský » vs "mad'arský», décalque du couple vlast'/otčina. Un article du Nyitravármegye, proche du parti libéral de Tisza, intitulé « Les Slovaques de Nitra » offre une bonne synthèse de ce regard porté sur le combattant slovaque des premiers mois de la guerre dans la presse: «De toutes les nationalités, ce sont les Slovaques qui sont les plus proches du cœur hongrois. Il nous sont tellement proches qu'il est impossible de nous en séparer. Nous sentons comment nos coeurs battent de concert. [...] Ils ont montré non seulement qu'ils peuvent être des Hongrois, mais aussi qu'ils souhaitent rester avec nous, dans la paix comme dans la guerre. Ils nous ont offert leur concours, ont sacrifié leur vie, leur sang dans le combat contre l'ennemi commun [...], nous nous soutenons mutuellement [...] parce que nous ne faisons qu'un, parce que nous sommes Hongrois. Parce que le Slovaque est Hongrois. Depuis des siècles il vit avec nous, depuis des siècles, il est notre pain, il vit sur notre terre, depuis des siècles sous notre protection..$^{30}$ »

Dans son analyse de la presse hongroise de l'époque, l'historien Laco Vörös tire quelques éléments sur la représentation alors la plus commune : d'une part, la guerre est conçue comme permettant l'achèvement du travail d'unification de la nation hongroise mené depuis plusieurs générations et fait de la nation hongroise une réalité. D’autre

\footnotetext{
${ }^{25}$ Milan Zemko in « Dejiny Slovenska v dejinách Slovenska », débat des Slovenské Pohl'ady, 10/1992, p. 17.

${ }^{26}$ Voir notamment le recueil d'études de Dušan Škvarna, Cesta moderných slovenských dejín, Banská Bystrica, Univerzita Mateja Bela, 2007.

${ }^{27}$ Voir notamment Peter Macho, Milan Rastislav Štefánik v hlavách a srdciach, Bratislava, HÚ SAV, 2011 ; Gabriela Kiliánová, Identita a pamät'. Devín/Theben/Dévény ako pamätné miesto, Bratislava, Ústav etnológie SAV, 2005 ; Miroslav Michela, «Percepcia svatého Štefana na Slovensku v medzivojnovom období », in M. Hlavačka, A. Marès, M. Pokorná (dir.), Pamět' míst, události a osobností: historie jako identita a manipulace, Prague, Historický ústav, 2011, p. 218-242 ; Martin Brtko, « Pamätník v Darney jako miesto pamäti », in ibid, p. 375-391.

${ }^{28}$ Pour les essais les plus synthétiques, voir Adam Hudek, Najpolitickejšia veda. Slovenská historiografia v rokoch 1948-1968, Bratislava, HÚ SAV, 2010.

29 Ján Lajčiak, op. cit., p. 53.

${ }^{30}$ Nyitravármegye, 4 décembre 1914, cité par Laco Vörös, « Premeny obrazu Slovákov v mad'arskej hornouhorskej regionálnej tlači v období rokov 1914-1918 », Historický časopis, 54e année, nº 3/2006, p. 435.
} 
Quelques réflexions sur la difficulté à concevoir l'étranger en Europe centrale...

part, le peuple slovaque refuse le panslavisme. Enfin, la « société slovaque » est dépeinte comme une société active, contrairement à l'image de masse passive qui dominait avant 1914. ${ }^{31}$ Mais, dans un premier temps, d'autres éléments de la représentation restent inchangés : c'est le cas en particulier de l'opposition entre le " peuple pacifique et loyal » et les « agitateurs panslaves » qui prétendent parler en leur nom. Cette approche se modifia au cours de l'année 1917.

Les événements intervenus en Pays tchèques en mai 1917 qui traduisaient un début de synergie entre l'action extérieure de Masaryk et du Conseil national des Pays tchèques d'un côté, et la politique tchèque en Autriche-Hongrie d'un autre, eurent un impact important sur l'attitude hongroise à l'égard des Slovaques. Le gouvernement et les autorités hongroises critiquèrent le silence qui l'avait suivi et exigèrent des Slovaques qu'ils renouvellent l'expression de leur loyauté à l'égard de la patrie hongroise, " afin d'écarter toutes les incompréhensions et tous les doutes, pour envoyer de nouveau un message clair de refus de l'irrédentisme tchèque ${ }^{32} »$. La presse hongroise de Slovaquie joua alors d'un argument qu'elle savait porteur dans le contexte slovaque de l'époque : la crainte de l'assimilation par les Tchèques. «L'objectif des Tchèques est la destruction et l'assimilation de la nation slovaque ${ }^{33} »$. On trouve ici le souci pour l'altérité slovaque (plus exactement, l'apparence du souci). La condition du maintien de l'identité politique - l'existence du royaume de Hongrie - suppose ici la reconnaissance de l'altérité. Céder aux sirènes tchèques reviendrait à mener une "politique suicidaire ". Après que Poincaré a autorisé la constitution de forces armées tchécoslovaques, le 16 décembre 1917, Liptó reprit cette antienne : "En agissant ainsi, les Tchèques veulent à tout prix compromettre les Slovaques, ils visent à démontrer la vérité de ce mensonge qui consiste à affirmer que Tchèques et Slovaques forment une seule nation. [...] Une telle présentation des Slovaques ne peut avoir de conséquences que très désagréables (pour les Slovaques, nda) si leurs dirigeants ne s'élèvent pas avec la plus grande énergie contre cette tactique des traîtres tchèques ${ }^{34}$. » Accepter l'identité avec les Tchèques - telle qu'elle résulte du projet masarykien - présenterait pour les Slovaques le risque de devenir étranger à euxmêmes. Incidemment, les dirigeants du SNS ne sont dès lors plus considérés comme de dangereux traîtres panslaves à opposer au peuple loyal et travailleur, mais comme des responsables qui doivent prendre la mesure du risque de dilution nationale en cas de concrétisation du «projet tchèque » et, par conséquent, réaffirmer l'importance du lien à la patrie hongroise. Cette situation provoque un nouveau glissement. Les Slovaques sont de nouveau considérés comme une nationalité, indépendante, qui n'appartient en aucun cas à la nation tchèque ou à la nation tchécoslovaque. Implicitement, ils sont ainsi placés à part de la nation hongroise et la distinction "uhorský-mad'arský ", un temps disparue, est réintroduite.

L'affirmation d'une irréductible altérité entre Tchèques et Slovaques n'est pas portée par les seuls discours officiels hongrois ou la presse qui les relaient. Au cours de l'automne 1918, avec des différences notables selon les territoires, la tension provoquée par l'imminence de la défaite des puissances centrales s'accompagna d'une campagne virulente contre l'hypothèse tchécoslovaque. Ce fut en particulier le cas dans le Spiš. ${ }^{35}$

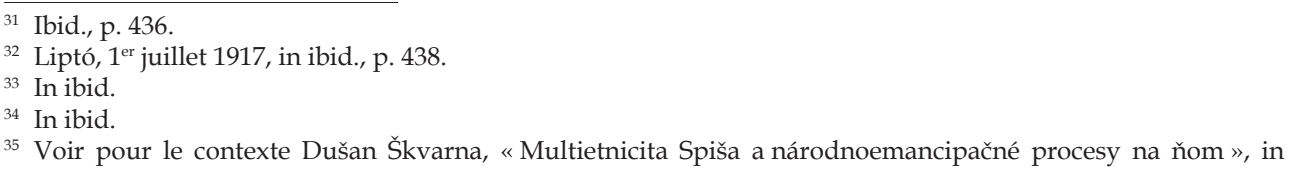


Les Allemands y étaient beaucoup plus pro-hongrois, orientation marquée dès le départ, lors de la création des Conseils nationaux locaux, par des proclamations favorables au maintien de l'intégrité du royaume de Hongrie. Dans une communauté allemande très active, on trouve des formes de dépréciation des masses slovaques sans culture : "Tout ce qui est et reste ici a été fait par les Allemands, le pays, la terre sont pour leur majeure partie dans des mains allemandes et hongroises et, dans tout le Spiš, il n'y a pas un homme éduqué qui se revendiquerait de la slovacité ! [...] Nous étions Allemands, nous sommes Allemands, et nous voulons rester Allemands! Et c'est en tant qu'Allemands que nous étions Hongrois, que nous sommes Hongrois et voulons le rester ${ }^{36}$. » Et de la menace de domination tchèque brandie comme un avertissement aux Slovaques dans les derniers mois, on trouve encore des traces dans cette presse régionale allemande : «En Hongrie, pendant le millénaire de domination hongroise, vous étiez et êtes restés Slaves [entendre «Slovaques » dans le contexte] ! Êtes-vous convaincus qu'il en sera ainsi après un siècle seulement de domination tchèque ? $^{37}$ " Mais, signe $d^{\prime}$ un attachement qui ne repose pas seulement sur l'appartenance au royaume, l'idée d'autonomie du Spiš réduit à sa composante hongroise et allemande est exprimée début décembre 1918 dans le Karpathen-Post comme alternative à l'incapacité du gouvernement hongrois à les défendre. La situation s'apaisa peu à peu, sans pour autant limiter les expressions d'un fort particularisme régional. La difficulté d'inclusion dans le périmètre national fut patente dans les régions orientales de Slovaquie où l'appareil administratif tchécoslovaque dû tenir compte d'une forme d'altérité qui s'exprimait sous des formes particulières. ${ }^{38}$

Mais ici encore, passer l'ensemble du territoire et de ses populations sous une même toise serait erroné. Un autre cas de figure, parmi les très nombreux qui surviennent au moment du "Prevrat ${ }^{39}$ ", est l'adaptation parfois rapide d'un appareil administratif aux nouvelles conditions politiques, ce dont atteste une partie des correspondances du ministère pour l'administration de la Slovaquie, y compris dans des régions considérées comme indiscutablement slovaques, l'Orava en l'occurrence. C'est ce que suggèrent les mémoires d'Ivan Thurzo ${ }^{40}$ qui permettent d'approcher la complexité de ce qui se joue dans les liens multiples autour de la question dite "nationale », avant comme après 1918 : « Dans la société slovaque de Martin, les mots de Janko Izák - „Dans l’Orava les Slovaques sont aussi magyarons, en même temps que les magyarons sont Slovaques" - était devenus pour ainsi dire proverbiaux. Dans l'Orava, il n'y avait pas de séparation entre l'intelligentsia slovaque d'un côté et hongroise ou magyarone de l'autre comme cela pouvait exister dans les autres régions slovaques ${ }^{41}$.» [...] « Le comitat de l'Orava fut le seul où les noms des localités n'avaient pas été magyarisés et, après le

R. Gladkiewicz, M. Homza (dir.), Terra Scepusiensis: stav bádania o dejinách Spiša, Levoča - Wrocław, Lúč, 2003, p. 671-678.

${ }^{36}$ Karpathen-Post, 24 octobre 1918 ; M. Bobrík « Nemci na Slovensku a slovenská otázka počas a po skončení prvej svetovej vojny (1916-1919) ", in H. Mommsen, Dušan Kováč, Jiří Malíř (dir.), Proní světová válka a vztahy mezi Čechy, Slováky a Němci, Brno, Matica moravská, 2000, p. 110.

37 Karpathen-Post, 31 octobre 1918, in ibid.

${ }^{38}$ Erik Dulovič, « Realizácia štátnej politiky županov Košickej župy v rokoch 1923-1928 », Historický časopis, 53e année, n 4/2005, p. 659-696.

39 Voir sur ce sujet, K. A. Medvecký, Slovenský prevrat (Trnava, 1930) en particulier son volume IV ; Ismo Nurmi (1999), op. cit.; Miroslav Michela, Pod heslom integrity, Bratislava, Kalligram, 2009.

${ }^{40}$ Ivan Thurzo, Medzi vrchmi a na rovine, Bratislava, Tatran, 1987

${ }^{41}$ In ibid., p. 32. 
Quelques réflexions sur la difficulté à concevoir l'étranger en Europe centrale...

Prevrat, les employés de l'administration s'engagèrent dans les services slovaques et, habilement, prirent part à toutes les actions slovaques d'éducation ${ }^{42}$. »

La difficulté à saisir la fluidité des relations et l'extrême ductilité de la composante « étrangère » ne sont pas limitées à ces seuls exemples. Les territoires aujourd'hui méridionaux de la Slovaquie, mais qui dans le royaume de Hongrie font le lien entre l'orbite de Budapest et les régions « slovaques » du nord, en sont une autre illustration, aujourd'hui très étudiée.

Il existe plusieurs séries de combinaisons de représentations de cet espace, selon les configurations politiques et historiographiques. Les catégories mobilisées dans les discours politiques - slovaques ou hongrois - montrent néanmoins qu'il n'y a pas un sud, mais des sud qui, avant 1918, n'entrent pas, pour leur plus grande partie, dans la " province » définie par le Mémorandum de 1861. Pour périphérique qu'il soit, il n'est pas exclu d'un espace mental qui court du Danube aux Tatras, de la Morava à la rivière Uh. Son intégration dans le récit national, même tardive, n'est pas artificielle. À partir de 1918, c'est un territoire slovaque, dont il est dit avec force qu'il fut largement magyarisé au XIX ${ }^{e}$ siècle, mais dont il est possible d'assurer le retour dans le giron national. ${ }^{43}$ Cette " slovacité » récemment perdue est un des topos associé à l'étude de l'impact de la magyarisation avant la Première Guerre mondiale et il fut d'ailleurs l'un des arguments de la délégation tchécoslovaque à la conférence de la paix de Paris. ${ }^{44}$

Après la création de la Tchécoslovaquie, ce territoire en particulier concentra une partie de l'attention liée aux craintes d'une articulation ente l'autonomisme de certains et l'irrédentisme d'autres. Par là même est introduite une partie d'un discours de méfiance/défiance à l'égard des citoyens magyarophones qui se superpose à l'élaboration du récit national tchécoslovaque héroïsé, élaboré autour de la notion de «libération », absente avant 1914.

Sans préjuger d'autres phénomènes d'exclusion ou minorer les effets d'une instrumentalisation de catégories, qu'elles soient « nationales » ou autre, il semble utile de modérer une approche trop clivante de la catégorie " étranger » dans le contexte slovaque du début du $\mathrm{XX} \mathrm{X}^{\mathrm{e}}$ siècle. Pour être plus précis, dans la mesure où plusieurs travaux récents précisent la nature des clivages, il faut éviter d'en faire une analyse trop segmentante, replacer les catégories utilisées en s'abstrayant autant que possible des strates historiographiques successives qui ont imposé une lecture binaire - même si les modalités en sont variables - des relations entretenues entre les différentes catégories de population du territoire de l'actuelle Slovaquie.

\section{Bibliographie}

BAKKE, Elisabeth (1999), Doomed to Failure? The Czechoslovak nation project and the Slovak autonomist reaction 1918-38, Oslo, Series of Dissertation submitted to the Department of Political Science, Faculty of Social Sciences, University of Oslo, $n^{\circ} 11 / 1999$.

BoвRík, M., « Nemci na Slovensku a slovenská otázka počas a po skončení prvej

\footnotetext{
${ }^{42}$ In ibid, p. 34.

${ }^{43}$ Elena Mannová, «Southern Slovakia as an Imagined Territory », in Steven G. Ellis, Raingard Esser (dir.), Frontiers, regions and identities in Europe, Pise, Plus-Pisa university press, 2009, p. 185-204.

${ }^{44}$ Voir notamment Fedor Houdek, Vznik hraníc Slovenska, Bratislava, 1930.
} 
svetovej vojny (1916-1919) ». In : Mommsen, H. - Kováč, Dušan - MaLíř, Jiří (éds.) (2000), Proní světová válka a vztahy mezi Čechy, Slováky a Němci, Brno : Matica moravská.

BoIsSERIE, Étienne (2010), « Les Voies étroites d'une historiographie nationale. La construction d'un canon historique slovaque au XIX ${ }^{\mathrm{e}}$ siècle ». In : MAsLOWSKI, Michel - Gradvohl, Paul - FrancFort, Didier (éds.), Canons de la culture et visions de l'histoire en Europe centrale, Paris : Institut d'études slaves, 305-326.

BoIsserie, Étienne - ROYer, Clara (éds.) (2011), Miroirs brisés, Récits régionaux et imaginaires croisés sur le territoire slovaque, Paris : Institut d'études slaves - CIRCE.

BRTKO, Martin (2011), « Pamätník v Darney jako miesto pamäti ». In: HLAVAČKA, Milan - Marès, Antoine - PокоRnÁ, Magdaléna (éds.), Pamět míst, události a osobností: historie jako identita a manipulace, Prague : Historický ústav, 375-391.

CzAmbel, Samuel (1906), Slovenská reč a jej miesto v rodine slovanských jazykov. I. Východoslovenské nárečie, T. S. Martin : Kníhtlačiarsky účastinársky spolok (KÚS).

DAXNER, Štefan Marko (1861), Hlas zo Slovenska, Pest : Trattner-Károly.

Dérer, Ivan (1935), Československá otázka, Prague : Orbis.

Dulovič, Erik (2005), « Realizácia štátnej politiky županov Košickej župy v rokoch 1923-1928 », Historický časopis 53, n 4, 659-696.

FRANKOVÁ, Libuša (2006), « K formovaniu predstáv o slovenskom etnickom území v národných obranách v prvej polovici 19. storočia ». In : Dejiny (Internetový časopis Inštitútu histórie FF PU v Prešove), n 1, 7-15.

HaLÁsz, Ivan (2011), Uhorsko a podoby slovenskej identity v dlhom 19. storočí, Bratislava : Kalligram.

HoudeK, Fedor (1930), Vznik hraníc Slovenska, Bratislava.

HRUŠOvSKÝ, František (1939), Slovenské dejiny, T. S. Martin : Matica slovenská.

HudEK, Adam (2010), Najpolitickejšia veda. Slovenská historiografia v rokoch 1948-1968, Bratislava : HÚ SAV.

KiLIÁNovÁ, Gabriela (2005), Identita a pamät'. Devin/Theben/Dévény ako pamätné miesto, Bratislava : Ústav etnológie SAV.

KiliánovÁ, Gabriela - Kowalská, Eva - KReKovičová, Eva (éds.) (2009), My a tí druhí $v$ modernej spoločnosti, Bratislava: Veda.

LAJČIAK, Ján (2007), Slovensko a kultúra, Bratislava : Q111 (1 $1^{\text {re }}$ édition, Bratislava : Slov. Ev. a v. Theol. Akademia, 1920).

MACHO, Peter (2011), Milan Rastislav Štefánik v hlavách a srdciach, Bratislava : HÚ SAV.

MANNOVÁ, Elena (2009), «Southern Slovakia as an Imagined Territory ». In : G. ELLIS, Steven - EsSER, Raingard (éds.), Frontiers, regions and identities in Europe, Pisa : Plus-Pisa university press, 185-204.

ManNovÁ, Elena (2007), « Koncept lojality. Postoj k autoritám na Slovensku počas prvej svetovej vojny », Historický časopis 55, n 4, 681-698.

Maxwell, Alexander (2009), Choosing Slovakia. Slavic Hungary, the Czechoslovak Language and Accidental Nationalism, Londres \& New York, I.B. Tauris Publishers.

MedveckÝ, Karol Anton (1931), Slovenský prevrat. Zv. IV, Trnava.

Michela, Miroslav (2009), Pod heslom integrity, Bratislava : Kalligram.

Michela, Miroslav (2011), « Percepcia svatého Štefana na Slovensku v medzivojnovom období ». In : HLAVAČKA, Milan - Marès, Antoine - POKORNÁ, 
Magdaléna (éds.), Pamět míst, události a osobností: historie jako identita a manipulace, Prague : Historický ústav, 218-242.

NiederLe, Lubor (1903), Národopisná mapa uherských Slováků na základě sčitání lidu z roku 1900, Praha.

Nurmi, Ismo (1999), Slovakia - A Playground for Nationalism and National Identity 1918-1920, Helsinki : Suomen Historiallinen Seura.

PodrimavsKÝ, Milan (1983), Slovenská národná strana v druhej polovici 19. storočia, Bratislava : Veda.

SASINEK, František Vit’azoslav (1905), Slováci v Uhorsku, Turčiansky Sväty Martin : KÚS, 1905 (2 édition, revue et corrigée)

SASINEK, František Vit'azoslav, Dejepis Slovákov, Ružomberok : Karol Salva.

SzARKA, László (1999), Szlovák nemzeti fejlődés - Magyar nemzetiségi politika 1867-1918 / Slovenský národný vývin - Národnostná politika v Uhorsku 1867-1918, Bratislava : Kalligram.

ŠKVARNA, Dušan (2003), « Multietnicita Spiša a národnoemancipačné procesy na ňom ». In : GladKIEWICZ, R. - Homza, M. (éds.), Terra Scepusiensis: stav bádania o dejinách Spiša, Levoča - Wrocław : Lúč, 671-678.

ŠKVARnA, Dušan (2007), Cesta moderných slovenských dejin, Banská Bystrica : Univerzita Mateja Bela.

Švorc, Peter (ed.) (1995), Spiš v koninuite času, Prešov - Wien : Universum.

Thurzo, Ivan (1987), Medzi vrchmi a na rovine, Bratislava : Tatran.

VöRÖs, Ladislav (2001), Slováci v národnostnej politike Štefana Tiszu v rokoch 19131917 [Diplomová práca]. Filozofická fakulta univerzity Komenského - Katedra slovenských dejín a archivníctva, Bratislava.

VÖRÖS, Ladislav (2006), " Premeny obrazu Slovákov v mad'arskej hornouhorskej regionálnej tlači v období rokov 1914-1918 », Historický časopis 54, n³, 419-450.

VöRÖs, László (2010), Analytická historiografia versu nárdné dejiny. „Národ" ako sociálna reprezentácia, Pisa : Pisa University Press.

Zемко, Milan (1992), « Dejiny Slovenska v dejinách Slovenska », Slovenské Pohl'ady $\mathrm{n}^{\circ} 10$.

Étienne Boisserie

Institut national des langues et civilisations orientales

65 rue des Grands Moulins

75214 Paris Cedex 13

France

eboisserie@gmail.com 